\title{
Adaptation of Tongue Function in Surgically Treated Cleft Patients - Motion Mode Ultrasonographic Study
}

\author{
Dr. M.Rekha ${ }^{1}$, Dr. T. Dinesh Kumar ${ }^{2}$, Dr. R. Manikandhan ${ }^{3}$, Dr.P.C.Rajaram ${ }^{4}$ \\ ${ }^{1}$ Professor, Department of OMFS, Sri venkateswara Dental College, Puducherry-605102. \\ ${ }^{2}$ Professor \& HOD, Sree Lakshmi Narayana Institute of Medical sciences, Puducherry- 605102. \\ ${ }^{3}$ Professor \& Project Director, Meenakshi Cleft \& Craniofacial Unit, Meenakshi Ammal Dental college \& \\ Hospitals, Chennai \\ ${ }^{4}$ Head of the Department, Department of Radiology, Meenakshi General Hospitals, Chennai.
}

\begin{abstract}
:
Aims \& Objectives: To assess the functional efficiency and adaptation of tongue musculature in surgically treated cleft Patients by measuring the amplitude of contraction, fractional shortening of tongue musculature and to compare the changes in functional adaptive efficiency following surgery using m-mode ultrasonography. Methods: The study was carried out on 90 cleft patients both with complete (Type 1 - 47 patients) and incomplete cleft defects (Type 2 - 43 patients). The patients were divided into 3 groups- 30 each based on age i.e., Group 1: 5-10 yrs, Group 2: 10-15 years, Group 3: 15-20 yrs Tongue muscle function was evaluated in various phases of swallowing- tip, body and basal portions of the tongue using 2-D and M-Mode Ultrasonography and the results were analyzed statistically.

Results: There was a statistically significant difference in the fractional shortening of tongue musculature during swallowing in surgically treated cleft patients indicating adaptation of tongue function.

Conclusion: Te functional efficiency of tongue improved in surgically treated cleft patients which showed that the tongue merely adapts to environmental changes. So, the difficulty in speech in such patients should be attributed primarily to defective mechanisms in velopharyngeal function.
\end{abstract}

Keywords: M-Mode Echomyography, Fractional shortening, Swallowing.

\section{Introduction}

Cleft patients exhibit adaptations in the physiological patterns of swallowing and speech (vowel production). The ability of tongue musculature to compensate for the palatal defect thereby aiding in swallowing and speech draws attention.

Though there are several techniques to evaluate tongue function like cine radiography ${ }^{1}$ electropalatography, EMA ${ }^{2}$, EMMA, MRI ${ }^{3}$, 3-D CT scans ${ }^{4}$, Tele fluoroscopy studies ${ }^{5}$, each has its own disadvantages. Ultrasonography ${ }^{6,7}$ has the advantage of allowing visualization of the actual soft tissues of the tongue and floor of the mouth. M-mode or Motion mode in Ultrasonography ${ }^{8}$ is an excellent imaging device and provides the means to monitor and display information relative to muscle motion.

\section{Materials And Methods}

The study included 90 cleft patients with complete (47 cases) and incomplete (43 patients) palatal defects. The patients belonged to the age group of 4 yrs to 30 yrs. They were divided into 3 age groups of 5- 10, 10-15, and 15-20 yrs of age (selected in a way that 30 patients were there in each group). Among these patients, 47 of them had complete cleft palate with cleft of the lip and alveolus and 43 patients had incomplete cleft palate. One patient gave a personal history of cleft palate repair but presented with a large fistula in the anterior part of the palate and was included in the study. A through clinical examination as to the nature and type of defect was made and the findings were recorded.

A Philips HDI 1500 ultrasound unit with color Doppler and linear transducer probe 5-12 mega hertz was used for the study. The probe was positioned in the sub mental region (Fig.1) in a sagittal plane and the contractions and relaxations of tongue musculature during swallowing of saliva in various phases of swallowing were assessed and recorded as m-mode images both before and after surgery $y^{9,10,11,12}$ at the tip (phase -1 , body(phase-2) and basal portions(phase-3) of the tongue. 


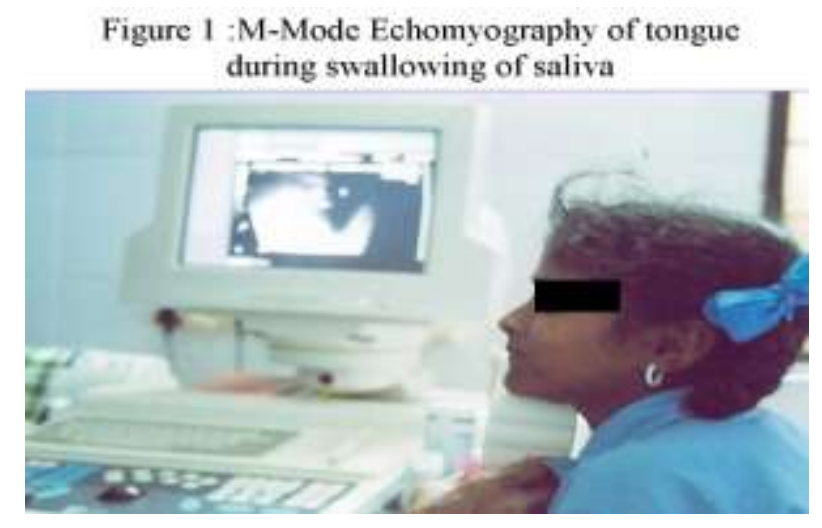

The values of amplitude and fractional shortening were tabulated and analyzed statistically (Table -1). The values of Fractional shortening were calculated by the formula,

Amplitude of contraction

Fractional shortening $=$

Thickness of relaxed muscle

Table - 1 M-Mode Echomyography of Tongue Function during Swallowing Of Saliva C-CONTRACTION R-RELAXATION A-AMPLITUDE OF CONTRACTION FS - FRACTIONAL SHORTENING Group 1: 0-10 Years Group II: 10-20 years Group III: 20-30 Years (SAMPLE OF 15 PATIENTS \& TOTAL - 90 PATIENTS)

\begin{tabular}{|c|c|c|c|c|c|c|c|c|c|c|c|c|c|c|c|c|c|c|c|c|c|c|c|c|c|c|}
\hline & & \multirow{2}{*}{$\begin{array}{l}\mathrm{S} \\
\mathrm{N} 0\end{array}$} & \multicolumn{8}{|c|}{ PHASE-1 } & \multicolumn{8}{|c|}{ PHASE-2 } & \multicolumn{8}{|c|}{ PHASE-3 } \\
\hline & & & \multicolumn{4}{|c|}{ PHEO? } & \multicolumn{4}{|c|}{ POSTOR } & \multicolumn{4}{|c|}{ PBEOP } & \multicolumn{4}{|c|}{ POSTOP } & \multicolumn{4}{|c|}{ PREOP } & \multicolumn{4}{|c|}{ POSTOP } \\
\hline $\begin{array}{l}\text { Theof } \\
\text { difect }\end{array}$ & Agp: & $\begin{array}{l}\mathfrak{s} \\
10\end{array}$ & C & R. & i & $\overline{B S}$ & C & P. & A & $\overline{F S}$ & c & $\begin{array}{ll}\text { R. } \\
\end{array}$ & A & $\overline{F S}$ & $\mathrm{C}$ & R & A & B & c & R. & A & $\bar{F}$ & C & \begin{tabular}{l|l} 
R. \\
\end{tabular} & A & $\mathrm{F}$ \\
\hline II & I & 1 & 280 & 362 & 088 & 2265 & 333 & 403 & 071 & 1736 & 284 & 431 & 1.7 & 3610 & 293 & 403 & 11 & 275 & 2.14 & 2111 & 0.67 & $21: 4$ & 295 & 3.68 & 0.73 & 19.83 \\
\hline 1 & I & 2 & 232 & 316 & 14 & 2658 & 253 & 3.11 & 163 & 1993 & 219 & 335 & 122 & 36.41 & 2.43 & 3.16 & 068 & $215 t$ & 24 & 352 & LIQB & 30.68 & 288 & 3.59 & 071 & 2017 \\
\hline I & I & $i$ & 270 & 3.75 & 105 & $28 \%$ & 295 & 3.64 & 071 & 1939 & 261 & 3.4 & 123 & 3203 & 295 & 321 & 099 & 85.12 & 29 & 3.60 & 131 & 3638 & $36 !$ & 455 & 084 & 2065 \\
\hline 1 & I & 4 & 289 & 300 & 100 & 2631 & 311 & 429 & 138 & 2750 & 26 & 396 & 136 & $3+60$ & 331 & 454 & 123 & 200 & 274 & 42 & 1.6 & 34.76 & 352 & 4.66 & 114 & 24.46 \\
\hline II & I & 5 & 4.17 & 326 & 091 & 218 & 407 & 105 & 165 & 2379 & 396 & 228 & 158 & 3939 & 4.04 & 278 & 134 & 3316 & 413 & 255 & 1.79 & 40.42 & 439 & 3.5 & 134 & 3052 \\
\hline II & II & 6 & 451 & $5 \mathrm{MA}$ & 053 & 10.51 & 381 & 4.86 & 0.65 & 181 & 33T & 398 & 0.61 & 1532 & 4.04 & 431 & 027 & 6.16 & 284 & 3.4 & 10 & 28.14 & \begin{tabular}{|l|l|}
3.4 \\
\end{tabular} & 439 & 099 & 2253 \\
\hline III & II & 9 & 30 & 415 & 145 & 27 & 281 & 3.12 & 031 & 993 & 274 & 452 & 1.79 & 3938 & 272 & 326 & 0.54 & 1636 & 18 & 3.7 & 19 & 5135 & \begin{tabular}{|l|}
216 \\
\end{tabular} & 291 & 0.75 & 57 \\
\hline 1 & II & 8 & 381 & 454 & 0.73 & $16 \mathrm{~W}$ & 311 & 3.8 & 0.8 & IIIS & 3.1 & 42 & 12 & 2890 & 281 & 3.59 & 078 & 2121 & 27 & 3.63 & 093 & 26.4 & 392 & 3.64 & 038 & 1043 \\
\hline II & II & 9 & 305 & 419 & $1 \mathrm{AM}$ & 272 & 334 & 401 & 1.67 & 1670 & 23 & 507 & 2.17 & 4280 & 302 & 401 & 099 & 2468 & 258 & 4.72 & 214 & 4533 & 267 & 4.11 & 134 & 33.4 \\
\hline I & II & 10 & 38 & 5.13 & 185 & $36: 16$ & 375 & 495 & 12 & 24.27 & 3.6 & 53 & 1.7 & 3207 & 3.6 & 524 & 164 & 319 & 31. & 4.89 & 1.79 & 36.80 & 363 & $5 \mathrm{SH}$ & 1.41 & 279 \\
\hline II & II & II & 232 & 394 & 162 & 41111 & 366 & 466 & 10 & 221 & 290 & 4.17 & 127 & $3 \% .45$ & 3.13 & 463 & 15 & 3239 & 28 & 4.17 & 137 & 32.15 & 2.78 & 3.98 & $1 \mathrm{d \gamma}$ & 3160 \\
\hline I & II & 12 & 401 & 486 & 185 & 17.18 & 34 & 491 & 152 & 3099 & 252 & 498 & 2.5 & 4939 & 3.6 & \begin{tabular}{|l|}
46 \\
\end{tabular} & 10 & 21.73 & 281 & 4.66 & 185 & 39.69 & 354 & 431 & 0.77 & 1786 \\
\hline 1 & III & 13 & 26 & 403 & 143 & 35.18 & 36 & $55 !$ & 181 & 34.66 & 331 & 416 & 0.85 & 21.43 & 425 & 504 & 0,9 & 1567 & 2.64 & 426 & 164 & 3831 & 3.4 & 433 & 13 & 286 \\
\hline 1 & III & 14 & 253 & 363 & 105 & 189. & 393 & 486 & 095 & 18.13 & 255 & 472 & 2.17 & 4597 & 4.13 & 5.4 & 091 & 1805 & 264 & 4.13 & 166 & 40.10 & 287 & 372 & 085 & 2284 \\
\hline I & III & 15. & 252 & 3.4 & 180 & 317 & 313 & 3.72 & 0.9 & 1596 & 401 & 469 & 0.68 & 14.49 & 3.19 & \begin{tabular}{|l|}
3,52 \\
\end{tabular} & 033 & 935 & 305 & 354 & 0.19 & $13: 4$ & 352 & t.j4 & 0.82 & $18.8 \%$ \\
\hline
\end{tabular}

\section{Results}

The Mean and standard deviation were estimated from the sample for each study group. Mean values were compared by student's paired " $t$ " test (Table -2) and one-way ANOVA appropriately. Multiple range tests by turkey HSD procedure were employed to identify the significant groups of $\mathrm{P}$ - values in which one-way ANOVA is significant. In the present study, $\mathrm{P}$ value $<0.05$ was considered as the level of significance. Both the mean amplitude and the fractional shortening of tongue muscle contraction were decreased in all cases (Figure 2) that were statistically significant in phases II \& III. ( $\mathrm{P}=0.046, \mathrm{P}<0.0001)$.

Table 2: Amplitude and Fractional shortening of Tongue Musculature (by using students paired' $\mathbf{t}$ ' test)

\begin{tabular}{|l|l|l|l|l|l|}
\hline & & Pre op & Post op & Change & P-value \\
\hline Amplitude & & & & & \\
\hline & Phase-1 & $1.15+-0.40$ & $1.06+-0.46$ & $0.09+-0.52$ & $0.50(\mathrm{NS})$ \\
\hline & Phase-II & $1.45+-0.54$ & $0.94+-0.40$ & $0.51+-0.52$ & $0.002(\mathrm{~S})$ \\
\hline & Phase-III & $1.41+-0.48$ & $0.98+-0.31$ & $0.43+-0.41$ & $0.001(\mathrm{~S})$ \\
\hline Fractional shortening & & & & & \\
\hline & & & & & \\
\hline & Phase-I & $26.51+-8.05$ & $21.13+-6.30$ & $5.37+-9.950$ & $0.046(\mathrm{~S})$ \\
\hline & Phase-II & $33.22+-10.29$ & $22.10+-7.40$ & $11.12+-9.44$ & $<0.0001(\mathrm{~S})$ \\
\hline & Phase-III & $34.58+-9.19$ & $23.70+-6.11$ & $10.87+-7.84$ & $<0.0001(\mathrm{~S})$ \\
\hline
\end{tabular}


Figure 2: Fractional shortening of muscle contraction

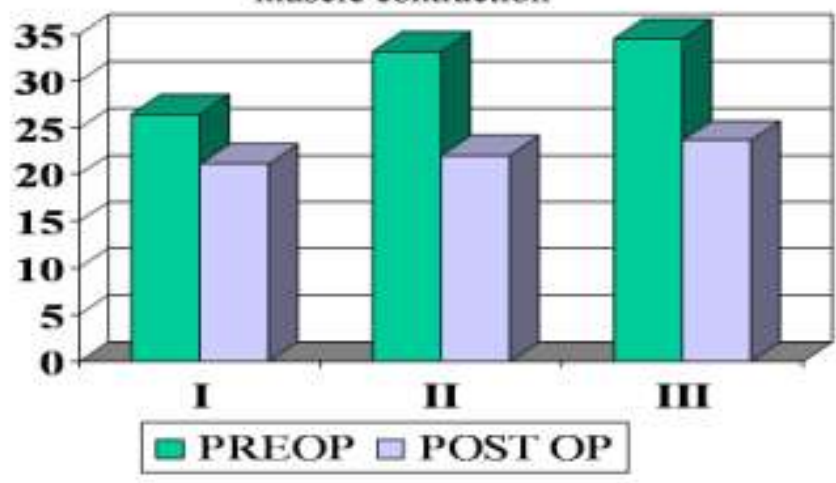

Group I (0-10 yrs) patients demonstrated a mean change in Fractional shortening of 4.80mm following surgery in all the phases, the change being more in phase III(Tables-3\&4). In group II (10-20yrs) patients, change in Fractional shortening was more in phase III and in group III patients change in Fractional shortening was more in phase II (Figure 3).

Table 3: Mean Fractional Shortening Before and After Surgery Vs Age Group I: 0-10 Yrs Group Ii: 10-20 Yrs Group Iii 20-30 Yrs

\begin{tabular}{|l|l|l|l|l|}
\hline AGE & STATUS & PHASE I & PHASE II & PHASE III \\
\hline \multirow{3}{*}{ I } & PRE OP & $25.02+/-2.68$ & $35.81+/-2.87$ & $33.22+/-6.30$ \\
\cline { 2 - 5 } & POST OP & $21.59+/-4.04$ & $25.88+/-4.73$ & $23.29+/-4.53$ \\
\hline \multirow{2}{*}{ II } & PRE OP & $25.13+/-11.12$ & $34.04+/-11.06$ & $37.19+/-9.05$ \\
\cline { 2 - 5 } & POST OP & $20.05+/-6.61$ & $22.09+/-8.93$ & $24.22+/-8.05$ \\
\hline \multirow{2}{*}{ III } & PRE OP & $32.05+/-3.29$ & $26.96+/-16.73$ & $30.75+/-14.67$ \\
\cline { 2 - 5 } & POST OP & $22.88+/-10.26$ & $15.83+/-2.15$ & $23.44+/-4.88$ \\
\hline
\end{tabular}

Table 4: Mean Change in Fractional Shortening Vs Age $\Psi \quad$ One Way Anova Test

\# Multiple Range Test by Turkey HSD Procedure

Group I: 0-10 Yrs Group II: 10- 20 Yrs Group III: 20 - 30 Yrs

\begin{tabular}{|c|c|c|c|c|c|c|c|c|c|}
\hline & PHASE I & $\Psi$ & \# & PHASE II & $\Psi$ & \# & PHASE III & $\Psi$ & \# \\
\hline Group I & $3.48+/-4.77$ & \multirow{3}{*}{$\begin{array}{l}0.74 \\
\text { (NS) }\end{array}$} & \multirow[t]{3}{*}{ Nil } & $9.93+/-3.62$ & \multirow{3}{*}{$\begin{array}{l}0.94 \\
(\mathrm{NS})\end{array}$} & \multirow[t]{3}{*}{ Nil } & $10.09+/-4.15$ & \multirow{3}{*}{$\begin{array}{l}0.59 \\
\text { (NS) }\end{array}$} & \multirow[t]{3}{*}{ Nil } \\
\hline Group II & $5.1+/-12.86$ & & & $11.95+/-11.19$ & & & $12.96+/-8.78$ & & \\
\hline Group III & $9.17+/-7.67$ & & & $11.14+/-14.61$ & & & $7.31+/-11.35$ & & \\
\hline
\end{tabular}

Figure 3: Mean Change in Fractional shortening

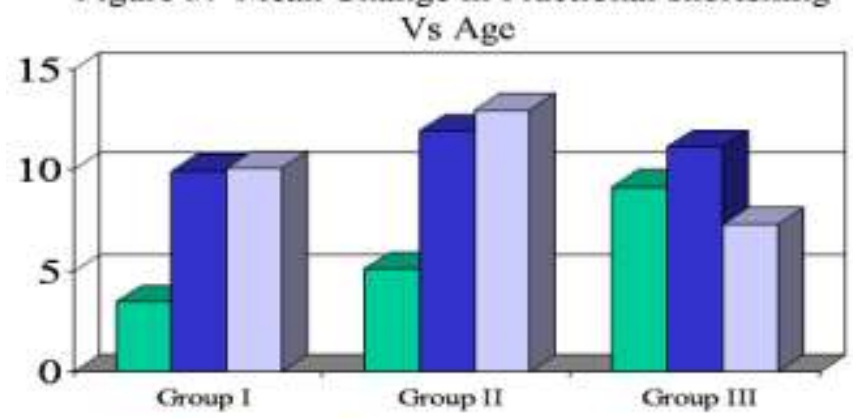

Phase I Phase II $\square$ Phase III

The mean change in Fractional shortening in all three phases was more in type I patients (Table -5). In type I patients, change in Fractional shortening was more in phase III, but in type II, it was more in phase I (Figure 4). 
Figure 4 Mean Change in Fractional shortening

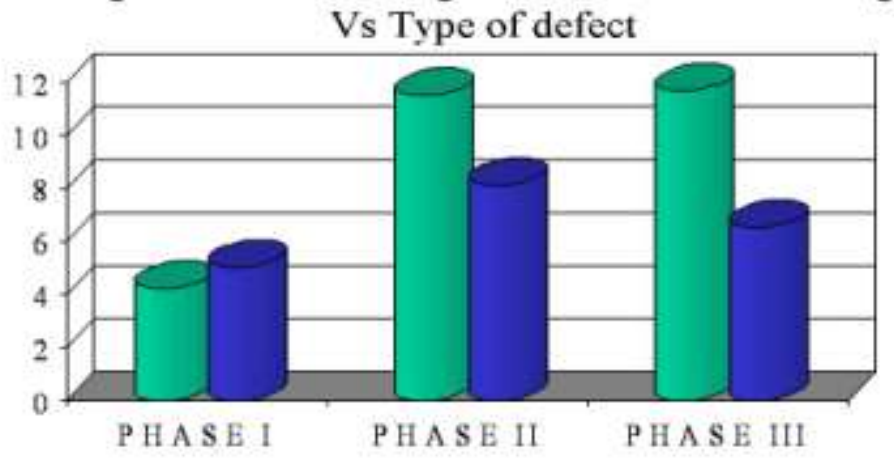

TYPEI $1 \mathrm{TYPEII}$

Table 5: Mean Change in Fractional Shortening Vs Type of Defect

\# -One way anova test
$\Psi$ - Multiple range test by turkey HSD procedure

Type I - Complete Cleft Type II - Incomplete Cleft

\begin{tabular}{|c|c|c|c|c|c|c|c|c|c|}
\hline & PHASE I & $\Psi$ & \# & PHASE II & $\Psi$ & \# & PHASE III & $\Psi$ & $\#$ \\
\hline TYPEI & $4.19+/-9.07$ & \multirow{2}{*}{$\begin{array}{l}0.43 \\
\text { (NS) }\end{array}$} & \multirow[t]{2}{*}{ NIL } & $11.48+/-10.37$ & \multirow{2}{*}{$\begin{array}{l}0.39 \\
\text { (NS) }\end{array}$} & \multirow[t]{2}{*}{ NIL } & $11.66+/-7.63$ & \multirow{2}{*}{$\begin{array}{l}0.06 \\
\text { (NS) }\end{array}$} & \multirow[t]{2}{*}{ NIL } \\
\hline TYPE II & $5.02+/-10.46$ & & & $8.11+/-7.15$ & & & $6.51+/-4.36$ & & \\
\hline
\end{tabular}

\section{Discussion}

The presence of a palatal defect impairs the complex physiological mechanisms of swallowing, breathing, hearing and speech. In 2002, C.L.Peng ${ }^{9}$ studied tongue movements during swallowing and divided the M-Mode images into 5 phases, according to each turn point between two different directions of tongue movement. But in the present study, the M-Mode images obtained were studied in three phases - the tip, body and the base of the tongue.

Also the five phases of tongue muscle contraction described by c.l.peng ${ }^{11,12}$ in 2002 according to each turn point between the two different directions at tongue movement cannot be used in cleft patients because the swallowing pattern is different in cleft patients, where the tongue contracts in various directions to various degrees to compensate for the palatal defect ${ }^{13}$.

The mean change in FS following surgery was more in type 1 patients with complete cleft where the tongue contracts as a whole to seal the palatal defect efficiently. The values of FS were less in group 1 (5-10 yrs) than in groups 2 and 3 patients as the tongue has to contract more to compensate for the bigger defect with increasing age. The study also showed that when compared to children and adults, the adaptive mechanism was more in adolescents.

FS was less in phase I (tip of tongue) because the tip was stabilized against the lingual surfaces of anterior teeth or the anterior palate, when the body and basal portions contract to seal the defect aiding in swallowing. The body of the tongue contracts in such a way that the dorsum of tongue becomes convex and rises up to seal the palatal defect while the base of the tongue aids in compensating for the posterior palate and the soft palate regions. Another interesting observation was that multiple contractions in the same direction were observed in a given phase and were termed as phase II a, II b, II c and so on. So there was a statistically significant decrease in FS of tongue musculature following surgery indicating an increase in functional efficiency in all three phases of swallowing.

\section{Conclusion}

The FS values of surgically treated cleft patients were close to normal patients which showed that cleft patients could achieve near normal, near physiological swallowing pattern following surgery ${ }^{13}$. Also, our observations suggest that the delay / absence in the restitution of phonation ${ }^{14}$ to satisfactory extent appear to be due to varying degrees of velopharyngeal incompetence despite satisfactory palatal repair ${ }^{15}$.

\section{References}

[1]. Miline IM, Cleau JF. Cine-fluorographic study of functional adaptation of oropharyngeal structures. Angle ortho. 1970; 40; 267-83.

[2]. Schonle PW, Grabe K. Electro magnetic articulography as a method for detecting the influence of on tongue movement Eur. J. Orthod. 1995; $17 ; 411-7$.

[3]. Lauder R, Muhl Z. Estimation of tongue volume from Magnetic resonance imaging. Angle Orthod 1991; 61: 175-83.

[4]. Lowe AA, Giohaka N, Takeuchi K, Fleetham JA. Three-dimensional CT reconstructions of the tongue and airway in adult subjects with obstructive sleep apnea. American J. orthod Dentofac. Orthop. 1986; 90; 364-74. 
[5]. Lawrence CW, Philips BJ. Telefluoroscopic study of lingual contacts made by persons with palatal defects. Cleft palate. J. 1975; Jan 12(00); 85-94.

[6]. RA Fuhrmann and PR Diedrich. B-Mode ultrasound scanning of tongue during swallowing. Dentomaxillofac Radio. 1994; 211-5.

[7]. Shawker TH,Sonies BC,Stone M et al. Real time ultrasound visualization of tongue movements during swallowing. J. Cli. Ultrasound. 1983; 11; 485-90.

[8]. PC Rajaram, EM Naidu, SP Rao, Sindhuvenugopal. M-mode Echomyography - A new technique for the functional assessment of striated muscles. Ind. J. Radiol Imag 2002; 12(4); 537 - 541.

[9]. Chia-Fen Cheng, Chien-Lun Peng. Dentofacial morphology and tongue function during swallowing. Am J orthod dentofacial orthop 2002; 122: 491-9.

[10]. Peng CL, Jest Brinkmann PG, Lin CT. Classification and interpretation of the oral swallowing phase with B+M mode ultrasound. Radiology 1995; 35: 747-52.

[11]. CL Peng, PG, Jest-Brinkmann PG. Ultrasonographic measurement of tongue movement during swallowing. Ultrasound Med. 2000; $19 ; 15-20$.

[12]. CL Peng, PG, Jest-Brinkmann PG, Miethke RR. The cushion scanning technique: a method of dynamic tongue sonography and comparison with the transducer - skin coupling scanning technique during swallowing. Acad. Radiology. 1996; 3: 239-44.

[13]. Henkel KO Dieckmann A, Gundlach KK. Primary swallowing function in relation to cleft type after 18 years of interdisciplinary therapy. Mund. Kiefer. Gesichtschir. 2002 Sep 6 (5): 314 - 8.

[14]. Yun-Chyun Chiang, Fel Peng Lee, Chien Lun Peng. Measurement of tongue movement during vowels production with computer assisted B-mode and M-mode ultrasonography. Otolaryngology Head \& Neck Surg.2003; Vol. 128; June N0.6; 805-814.

[15]. Massengill R Jr, Morawetz MJ, Pickrell K. Lingual positions of cleft palate patients with and without velopharyangeal closure. Folia. Phoniatr (Basel) 1970; 22(3): 185- 90. 